\title{
EFFECTIVENESS OF TRAINED HEALTH WORKERS IN IMPROVING THE ORAL HYGIENE OF PRESCHOOL CHILDREN
}

\author{
Dharmashree Satyarup ${ }^{1}$, Radha Prasanna Dalai ${ }^{l}$, Ramesh Nagarajappa ${ }^{l}$, \\ Debasruti Naikl, Ipsita Mohanty
}

\author{
${ }^{1}$ Department of Public Health Dentistry, Institute of Dental Sciences, Siksha 'O' Anusandhan \\ (Deemed to be University), Bhubaneswar, Odisha, India \\ ${ }^{2}$ Department of Oral and Maxillofacial Pathology, Institute of Dental Sciences, Siksha 'O' Anusandhan \\ (Deemed to be University), Bhubaneswar, Odisha, India
}

\begin{abstract}
Background. Poor oral health among children is common finding in the rural regions of India. But if the existent structure of primary health care is used, favourable oral health habits and importance of oral health can be instilled in the children and their parents at a very early stage.

Objective. To evaluate the effectiveness of Anganwadi workers (AWWs) in improving the oral hygiene of the preschool children through oral health education.

Material and methods. 250 children in the age group of 2.5-6 years, were included in the study. The study was conducted in three phases over a period of 8 months which included a follow up of six months. Baseline oral health was determined using a questionnaire assessing the oral hygiene practices and DMFT Index, Plaque Index and Gingival Index. This was re-assessed after 6 months using the same questionnaire and indices. Statistical significance was fixed at $p$ value $Ł 0.05$. Chi square and paired ' $t$ ' test were used to assess the difference in the variables after providing oral health education.

Results. Out of 250 children, with mean age of 4.24 years, majority were girls $(142,56.8 \%)$. The use of fluoridated toothpaste among the study population significantly increased from $34.4 \%$ to $41.5 \%$ ( $\mathrm{p}=0.001)$ with the intervention of oral health education (OHE). Decrease in consumption of sticky sugar, addition of sugar in the night-feeds and cleaning of teeth after night-feeds were also found to change significantly. Gingival index showed significant reduction after OHE $(\mathrm{p}=0.001)$.

Conclusion. The study revealed that training of Anganwadi workers (AWWs) could be used to improve the oral health of the Anganwadi children. They represent an untapped source for delivering oral care to rural communities that otherwise have limited access.
\end{abstract}

Key words: health workers, oral hygiene, oral health, oral health education

\section{INTRODUCTION}

Young children often are affected by poor oral health in early childhood, which is a cause of serious concern and expenditure [2]. In developing countries like India, majority of the population resides in rural areas, of which $40 \%$ are children. The children were most neglected when it came to oral health care services due to issues regarding availability and affordability. Knowledge regarding cause and prevention of oral disease is also deficient among parents and basic health care workers [6].

Integrated Child Development Services (ICDS) scheme introduced by Government of India is one of the world's largest programmes for early childhood development enhancing survival and development of children belonging to the susceptible and deprived sections of society. Under this, one Anganwadi centre (AWC) which is equivalent of a preschool in the rural areas, covers population of $400-800$ and is managed by Anganwadi workers (AWWs) who are basic healthcare workers. She/he is a person of same vicinity, selected by the people having basic educational qualifications. They are not government employees but are called "social workers" or "voluntary workers." Their important functions entail educating women with regard to institutionalized deliveries, postnatal care, benefits of breast feeding, immunization of the new-born, growth and development of the child, supplementary nutrition 
etc.[5] Once in a month AWWs come in close contact with the society especially women where they reside and can form a bridge between the society and health professionals. Since these Anganwadi workers have access to majority of the society, they should therefore be empowered regarding awareness of oral health so that they can disseminate the information and educate the mothers and their young ones.

Therefore, the present study was carried out to assess oral hygiene of the Anganwadi children following oral health education to Anganwadi workers after a period of 6 months.

\section{MATERIAL AND METHODS}

\section{Study Area}

The study was conducted among the 267 children of 10 AWCs under a rural division of Khorda district of Odisha, India. Of these, 250 children present on the day of baseline examination and aged between 2.5 to 6 years of age and whose parents provided informed consent were included as participants for the study.

\section{Study method}

The study was a before and after study, and was conducted in three phases over a period of 8 months extending from July 2017 to February 2018 with the intervention as oral health education.

1. Phase I. Pre-Oral Health Education (Pre-OHE): All the pre-school children were examined at baseline in the presence of a parent and respective AWW using a structured proforma. Dental caries, gingivitis and plaque was evaluated using dentition status by WHO [18], Gingival Index by Loe and Silness and Plaque Index by Silness and Loe modified for the deciduous dentition [15].

2. Phase II. Oral Health Education (OHE): Oral health education was provided to all AWW (ten in number), a month after the baseline examination. The benefits of imparting oral health guidance to the mothers of the children and reinforcing it frequently was emphasized.

3. Phase III. Post-Oral Health Education (Post-OHE): Follow up examination of 250 preschoolers was done after six months from the day of providing health education, using the same structured proforma. Improvement in oral hygiene practices, feeding practices and alterations in plaque and gingival index scores were considered as outcome indicators.

\section{Method of data collection}

Permission and scheduling: Study was conducted after formal permission from the office of District Social Welfare Officer. The investigator visited the AWC a week prior to the baseline examination in order to request cooperation and attendance of the Anganwadi workers on the day of the examination as per a pre-decided schedule.

Proforma used: A structured proforma specially designed was pretested and used to collect information at the baseline and follow-up examinations. The first section was designed to collect information regarding sociodemographic details and socio-economic status (revised B.G. Prasad and Udai Pareek classifications) [16] The next part collected data about oral hygiene history, sugar consumption and night feeding habits. The last portion of proforma recorded dental caries, plaque and gingivitis using indices. The feasibility and relevance of proforma was tested by a pilot study carried out on 20 children from AWCs of neighboring rural area who were not a part of the main study. The proforma was tested for reliability using Cronbach's $\alpha$ $(\alpha=0.75)$

Method of examination: The proforma was filled through responses of the mothers derived through a face to face interview by the investigator. The clinical examination for recording findings of the indices was done by a single examiner with the aid of an assistant to record the data. Training and calibration of the investigator was done by examination of 20 children on two consecutive days, the intra-examiner variability was between 0.76 to 0.82 using kappa statistics.

Oral health education: All the ten AWWS were provided oral health education using power point presentation over a duration of 35 minutes in local language. Content of oral education was modified to address the short comings assessed from the baseline responses and examination.

Ethical consideration: Informed consent was obtained from the parents before clinical examination of their child. Ethical clearance was obtained from the Institutional Ethical Committee.

\section{Statistical Analysis}

The data was transferred to excel sheet and then analyzed using SPSS version 20 to prepare descriptive tables, inferential tables and perform the tests of significance. Statistical significance was fixed at $\mathrm{p}$ value $\leq 0.05$. Paired ' $\mathrm{t}$ ' test and Chi square were used to calculate the difference in the variables after providing oral health education.

\section{RESULTS}

A total of 250 preschool children were examined in the age range of 2.5-6 years, with a mean age of $4.24 \pm 0.74$ years and most of them were girls (56.8\%). Table 1 depicts the sociodemographic specifics of the population.

An analysis of oral hygiene habits of the study population found $91.2 \%$ practiced oral hygiene using 
Table 1. Distribution of the study population according to the socio-demographic variables

\begin{tabular}{|c|c|c|c|c|}
\hline \multicolumn{3}{|c|}{ Socio-demographics } & Frequency (n) & Percentage $(\%)$ \\
\hline \multirow{3}{*}{ Age } & \multicolumn{2}{|c|}{2.5 - 3 years } & 22 & 8.8 \\
\hline & \multicolumn{2}{|c|}{$4-5$ years } & 216 & 86.4 \\
\hline & \multicolumn{2}{|c|}{ More than 5 years } & 12 & 4.8 \\
\hline \multirow{2}{*}{ Gender } & \multicolumn{2}{|c|}{ Male } & 108 & 43.2 \\
\hline & \multicolumn{2}{|c|}{ Female } & 142 & 56.8 \\
\hline \multirow{3}{*}{ Paternal education } & \multicolumn{2}{|c|}{ High school** } & 160 & 64.0 \\
\hline & \multicolumn{2}{|c|}{ Graduate } & 88 & 35.2 \\
\hline & \multicolumn{2}{|c|}{ Post graduate } & 2 & 0.8 \\
\hline \multirow{4}{*}{ Maternal education } & \multicolumn{2}{|c|}{ Illiterate** } & 26 & 10.4 \\
\hline & \multicolumn{2}{|c|}{ Primary school } & 62 & 24.8 \\
\hline & \multicolumn{2}{|c|}{ High school } & 94 & 37.6 \\
\hline & \multicolumn{2}{|c|}{ Graduate } & 68 & 27.2 \\
\hline \multirow{4}{*}{ Fathers occupation } & \multicolumn{2}{|c|}{ Business } & 86 & 34.4 \\
\hline & \multicolumn{2}{|c|}{ Independent profession* } & 54 & 21.6 \\
\hline & \multicolumn{2}{|c|}{ Cultivation } & 86 & 34.4 \\
\hline & \multicolumn{2}{|c|}{ Service } & 24 & 9.6 \\
\hline \multirow{2}{*}{ Type of family } & \multicolumn{2}{|c|}{ Nuclear } & 114 & 45.6 \\
\hline & \multicolumn{2}{|c|}{ Joint } & 136 & 54.4 \\
\hline Variable & Mean & SD & Min & Max \\
\hline Family income & 12246.40 & 5108.03 & 1800 & 22000 \\
\hline
\end{tabular}

*Occupation: categorized based on Udai Pareek revised scale. **Education and family type: categorized according to modification of Udai Pareek revised scale[6]

Table 2. Changes in oral hygiene habits of the study population, before and after OHE

\begin{tabular}{|c|c|c|c|c|c|c|c|}
\hline & \multicolumn{2}{|c|}{$\begin{array}{c}\text { Frequency of tooth } \\
\text { brushing }\end{array}$} & \multicolumn{2}{c|}{ Fluoridated tooth paste use } & \multicolumn{3}{c|}{ Amount of fluoridated tooth paste } \\
\hline & Once & Twice & Did not use & Used & $\begin{array}{c}\text { Full length } \\
\text { of bristles }\end{array}$ & $\begin{array}{c}\text { Half-length } \\
\text { of bristles }\end{array}$ & Pea sized \\
\hline Pre - OHE & $234(93.6 \%)$ & $16(6.4 \%)$ & $163(65.6 \%)$ & $85(34.4 \%)$ & $83(33.6 \%)$ & $24(9.6 \%)$ & $141(56.8 \%)$ \\
\hline Post - OHE & $209(83.6 \%)$ & $41(16.4 \%)$ & $145(58.5 \%)$ & $103(41.5 \%)$ & $71(28.6 \%)$ & $20(8 \%)$ & $157(63.4 \%)$ \\
\hline p-value & \multicolumn{2}{|c|}{$0.000^{*}$} & \multicolumn{2}{c|}{$0.001 *$} & & $0.000^{*}$ \\
\hline
\end{tabular}

Test applied - Chi square; *Highly significant

tooth brush and dentifrice. Oral health education seemed to have a positive influence on practice of oral hygiene with improvement in the frequency of brushing and optimal amount fluoridated toothpaste (Table 2).

Children who consumed sugar more than thrice were $23.2 \%$, with majority of them $(70.4 \%)$ eating sugar in between meals. The oral health education had a positive impact on sugar consumption by reducing its frequency and intake of sticky sugars (Table 3).

Bottle feeding was seen only in $14.4 \%$, out of which only $16.7 \%$ had night feeds with added sugar. But after oral health education by the AWWs, this significantly reduced to $5.6 \%$. While most of them (61.1\%) followed the habit of rinsing by giving plain water following these night feeds, $38.9 \%$ did not follow any method of cleaning. But health instructions from the AWWs to the mothers helped in significantly reducing this to $22.2 \%$ (Table 3).

Mean number of decayed teeth was $0.78(\mathrm{SD}=1.38)$ and overall DMFT was $1.23(\mathrm{SD}=1.7)$. There was no significant difference in the dental caries following oral health education but Plaque Index and Gingival Index scores decreased significantly (paired ' $t$ ' test; $p=0.000)$ post oral health education as depicted in Table 4. 
Table 3. Changes in the study population according to frequency of sugar consumption before and after OHE

\begin{tabular}{|c|c|c|}
\hline Frequency of consuming sugar & Pre - OHE & Post - OHE \\
\hline Once & $82(32.8 \%)$ & $82(32.8 \%)$ \\
\hline Twice & $70(28 \%)$ & $77(30.8 \%)$ \\
\hline Thrice & $40(16 \%)$ & $43(17.2 \%)$ \\
\hline$>$ Thrice & $58(23.2 \%)$ & $48(19.2 \%)$ \\
\hline $\mathrm{p}$ value & \multicolumn{2}{|c|}{$0.001^{*}$} \\
\hline Time of consuming sugar & Pre - OHE & Post - OHE \\
\hline With meals & $74(29.6 \%)$ & $113(45.2 \%)$ \\
\hline In between meals & $176(70.4 \%)$ & $137(54.8 \%)$ \\
\hline $\mathrm{p}$ value & \multicolumn{2}{|c|}{$0.001 *$} \\
\hline Form of sugar consumed & Pre - OHE & Post - OHE \\
\hline Solid & $106(42.4 \%)$ & $119(47.6 \%)$ \\
\hline Liquid & $80(32 \%)$ & $80(32 \%)$ \\
\hline Sticky & $64(25.6 \%)$ & $51(20.4 \%)$ \\
\hline $\mathrm{p}$ value & \multicolumn{2}{|c|}{$0.001^{*}$} \\
\hline Addition of sugar to night feed & Pre - OHE & Post - OHE \\
\hline Not added & $30(83.3 \%)$ & $34(94.4 \%)$ \\
\hline Sugar added & $06(16.7 \%)$ & $2(5.6 \%)$ \\
\hline p-value & \multicolumn{2}{|c|}{$0.002 *$} \\
\hline Cleaning teeth after night feed & Pre - OHE & Post - OHE \\
\hline Did not clean & $14(38.9 \%)$ & $8(22.2 \%)$ \\
\hline Cleaned & $22(61.1 \%)$ & $28(77.8 \%)$ \\
\hline p-value & \multicolumn{2}{|c|}{$0.001^{*}$} \\
\hline
\end{tabular}

Test applied - Chi square; *Highly significant

Table 4. Changes in the study population according to Gingival Index and Plaque Index scores, before and after OHE

\begin{tabular}{|c|c|c|c|c|}
\hline & Pre - OHE & Post - OHE & \multirow{2}{*}{ t-value } & p-value \\
\cline { 2 - 4 } & Mean (SD) & Mean (SD) & 7.791 & $0.001^{*}$ \\
\hline Plaque index & $0.163(0.257)$ & $0.08(0.272)$ & 5.843 & $0.001^{*}$ \\
\hline Gingival index & $0.077(0.2)$ & $0.03(0.217)$ & \\
\hline
\end{tabular}

Test applied - Paired 't' test; *Highly significant

\section{DISCUSSION}

AWWs act as a first point of contact between healthcare and the community and are a vital link in establishing oral health awareness in children and mothers. Hence, this study was undertaken with the objective of using health workers to impart oral health guidance to mothers and preschool children. The effect of OHE was measured by clinical examination of the children and which the study found to have a positive influence.

The most prevalent method of cleaning teeth among the children was the use of tooth brush and dentifrice. Easy availability of tooth pastes and tooth brush even in rural areas and commercial advertisements can be the reason behind this acceptable practice of oral hygiene.
This was similar with the observations of other studies $[4,11]$. Brushing in the night was seen in only $6.4 \%$ of our study population, which is comparable to the findings from another study by Raj et al. [11]

A study conducted by Naidu et al [8] in Trinidad found that most of the care-takers had a state of confusion and concern regarding use of fluoride dentifrice in children, therefore these points were taken into consideration while giving health education. OHE stressing the advantage of brushing teeth before bed and use of pea sized amount of fluoridated dentifrice in children older than 4 years was given. This might have resulted in improvement of their oral hygiene habits which was similar to the results of other studies $[11,12]$. 
Preschool children who had sugar intake of at least once a day were $32 \%$, with $23.2 \%$ of them having sugar consumption of more than thrice. Comparable results were also found in other studies by Albandar et al. [1] and Gaidhane et al. [4]. Most of the sugar intake in our study was eaten in between meals, increasing the risk of developing dental caries. But relatively the component of sticky sugars was minimal as, most of the sugar was consumed as biscuits or added sugar to meals or milk. The habit of sugary aerated drinks or chocolates and toffees was still negligible. Therefore, it was emphasized during the oral health education, the importance of continuing limiting sugar intake to home-made sweets and healthy sugars from fruits. Importance of restricting sugar intake to meal times was also highlighted. Hence it was observed following the OHE, the percentage of children eating sweets more than three times reduced considerably while those who had sugars once remained unchanged but consuming sugar twice and thrice increased by $2 \%$ and $1.2 \%$ respectively. This occurrence could be attributed to the fact that probably most of sugars eaten changed to being consumed with the three meals the child had during the day, thereby reducing the in-between meal intake to $54.8 \%$ from $70.4 \%$. A reduction in sugar intake after an intervention of health education was also seen in other studies $[3,9,14,17]$.

Bottle feeding is considered normal until 18 months of age [15]. Sometimes it is thought that children take more food if fed by bottle than by cup, hence mothers favor continuing bottle feeding not wanting to compromise on nutrition. Addition of sugar to bottle feeds and giving bottle feeds during the night as a source of comfort to sleep can be detrimental to teeth. Bottle feeding was seen only in $14.4 \%$, probably because the study population belongs to a semi-urban setting where feeding by bottle and use of pacifiers are not yet popular. Oral health education given to the AWWs after the baseline examinations was found to reduce the habit of adding sugar to the bottle feeds from $16.7 \%$ to $5.6 \%$ and increase the number of mothers who followed the bottle feed by giving plain water. An improvement in the feeding habits following health education was also observed by one another study by Sandhya et al. [7] .

No change was observed in the dental caries status even after oral health education' as chronic diseases such as dental caries cannot be evaluated over a short span of 6 months. Hence it can be suggested that further research should be undertaken to evaluate long term impacts of health education.

The effect of OHE on plaque scores and gingival scores were similar to findings by Priya et al and $R a j$ et al. $[10,11]$. This improvement in plaque and gingival score in preschool children can be attributed to better oral hygiene habits such as increase in the frequency of brushing subsequent to the health education given.

\section{Limitations:}

The study was conducted on a small sample and the subjects were not randomly selected. It was a before and after study where each child acted their own control. The improvement in oral health may be because of the children's and parent's response to the assessment and intention to provide the desired response (social desirability). Studies have indicated that AWWs are overworked with record keeping and insufficient monetary compensation [13]. Hence expecting their continued role in providing oral health guidance cannot be ascertained until some form of incentive is given.

\section{CONCLUSION}

The results of our study showed that AWWs can be used as competent oral health guides. Since Anganwadi workers serve as the first point of contact, empowering them aids in providing effective preventive oral care to the population through the existing health care structure, thereby eliminating the need to invest in costly dental care.

\section{Conflict of interest}

The authors declare no conflict of interest.

\section{Acknowledgments}

None.

\section{REFERENCES}

4. Albandar, J. M., Buischi, Y. A. P., Mayer, M. P., \& Axelsson $P .:$ Long-term effect of two preventive programs on the incidence of plaque and gingivitis in adolescents. J. Periodontol. 1994;65(6):605-610.

5. Edelstein B. L.: Dental care considerations for young children. Special Care In Dentistry: Official Publication of the American Association of Hospital Dentists, The Academy of Dentistry For The Handicapped, and The American Society For Geriatric Dentistry. 2002;22(3 Suppl):11S-25S.

6. Freitas-Fernandes, L. B., Novaes Júnior, A. B., Feitosa, A. C. R., \& Novaes, A. B. Effectiveness of an oral hygiene program for Brazilian orphans. Brazilian Dental Journal. 2002;13(1):44-48.

7. Gaidhane, A. M., Patil, M., Khatib, N., Zodpey, S., \& Zahiruddin, Q. S.: Prevalence and determinants of early childhood caries among the children attending the Anganwadis of Wardha district, India. Indian J. Dental Res. 2013;24(2):199-205. https://doi.org/10.4103/09709290.135944.

8. Gangawar Chanchal, Kumar Manish, L. N.: KAP toward oral health, oral hygiene and dental caries 
status among anganwadi workers in Bareilly City, Uttar Pradesh: A Cross-Sectional Survey. J. Dent Sci Oral Rehabil. 2014;5(2):53-57.

9. Kaur B.: Evaluation of oral health awareness in parents of preschool children. Indian J. Dental Res. 2009;20(4):463-465. https://doi.org/10.4103/09709290.59455

10. Muthyala PavaFna S., Shanthi M., Fareed N., Sudhir K., Krishna Kumar R.: Effectiveness of oral health education among primary health care workers at the primary health center in Nellore district, Andhra Pradesh. J. Indian Assoc Public Health Dent. 2014;12(2):74. https:// doi.org/10.4103/2319-5932.140252

11. Naidu R., Nunn J., \& Forde M.: Oral healthcare of preschool children in Trinidad: a qualitative study of parents and caregivers. BMC Oral Health. 2012;12: 27. https://doi.org/10.1186/1472-6831-12-27.

12.Petersen P. E., Peng B., Tai B., Bian Z., Fan M.: Effect of a school-based oral health education programme in Wuhan City, Peoples Republic of China. Int. Dent. J. 2004;54(1): 33-41. https://doi.org/10.1111/j.1875595X.2004.tb00250.x

13. Priya H., Acharya S., Kumar M., Bhat M., Purohit B.: Oral health status and treatment need among preschool children attending Anganwadi centres - a comparative study. Oral Health Prev Dent. 2012;10(4):355-363. https://doi.org/10.3290/j.ohpd.a28906

14. Raj S., Goel S., Sharma V. L., Goel N. K.: Short-term impact of oral hygiene training package to Anganwadi workers on improving oral hygiene of preschool children in North Indian City. BMC Oral Health. 2013; 13: 67. https://doi.org/10.1186/1472-6831-13-67

15. Rong W. S., Bian J. Y., Wang W. J., De Wang J.: Effectiveness of an oral health education and caries prevention program in kindergartens in China.
Community Dentistry and Oral Epidemiology. 2003;31(6):412-416. https://doi.org/10.1046/j.16000528.2003.00040.x

16. Sandhyarani M. C., Rao, U. C.: Role and responsibilities of Anganwadi workers, with special reference to Mysore district. Int. J. Environ. Sci. Technol. 2013;2(6):12771296. https://doi.org/10.1016/j.foodchem.2015.07.063

17. Shenoy, R. P., \& Sequeira, P. S.: Effectiveness of a school dental education program in improving oral health knowledge and oral hygiene practices and status of 12- to 13-year-old school children. Indian Journal of Dental Research: Official Publication of Indian Society for Dental Research. 2013;21(2):253-259. https://doi. org/10.4103/0970-9290.66652

18. Tandon S.: Textbook of Pedodontics. In Textbook of Pedodontics. Paras Medical Publisher 2009; (2nd ed), pp. 13-14.

19. Tulika Singh, Sanju Sharma, S. N.: Socio-economic status scales updated for 2017. Int. J Res Med Sci. 2017;5(7):3264-3267. https://doi.org/10.18203/23206012.ijrms20173029

20.Vangipuram, S., Jha, A., Raju, R., \& Bashyam, M.: Effectiveness of peer group and conventional method (dentist) of oral health education programme among 1215 year old school children - A randomized controlled trial. J. Clin. Diagnostic Res. 2016;10(5):ZC125-ZC129. https://doi.org/10.7860/JCDR/2016/17725.7844

21. WHO. |Oral health surveys - basic methods. 5th ed. World Health Organization 2013, ISBN 9789241548649, https:// www.who.int/oral health/publications/9789241548649/ en/

Received: 18.12 .2020

Accepted: 08.02.2021 